\title{
Attempting to avoid false memories in the Deese/Roediger-McDermott paradigm: Assessing the combined influence of practice and warnings in young and old adults
}

\author{
JASON M. WATSON, KATHLEEN B. MCDERMOTT, and DAVID A. BALOTA \\ Washington University, St. Louis, Missouri
}

\begin{abstract}
On each of five study-test trials, young and old adults attempted to memorize the same list of 60 words (e.g., bed, rest, awake), which were blocked according to their convergence on four corresponding associates. Half of the participants in each age group were given an explicit warning about the DRM paradigm prior to encoding and were asked to attempt to avoid recalling any associated but nonpresented words (e.g., sleep). Lists were presented auditorily at either a fast (1,250 msec/word) or a slow (2,500 msec/word) rate. Without a warning, the probability of veridical recall across trials increased for both age groups; however, the probability of false recall across trials decreased only for young adults. When a warning about false recall was provided, young adults virtually eliminated false recall by the second trial. Even though old adults also used warnings to reduce false recall on Trial 1, they were still unable to decrease false memories across the remaining four study-test trials. Old adults also reduced false recall more with slow than with fast presentation rates. Taken together, these findings suggest that old adults have a breakdown in spontaneous, self-initiated source monitoring as reflected by little change in false recall across study-test trials but a preserved ability to use experimenterprovided warnings or slow presentation rates to reduce false memories.
\end{abstract}

False memory paradigms can offer leverage on understanding the breakdowns in episodic memory that occur with healthy aging (see Balota, Cortese, et al., 1999; Budson, Daffner, Desikan, \& Schacter, 2000; Kensinger \& Schacter, 1999; Norman \& Schacter, 1997; Tun, Wingfield, Rosen, \& Blanchard, 1998; Watson, Balota, \& SergentMarshall, 2001). In general, studies have demonstrated that relative to young adults, healthy old adults have impaired veridical memory (i.e., memory for information that has been presented) but equivalent or enhanced false memory (i.e., memory for information that has not been presented). For example, in the Deese-Roediger-McDermott (DRM) false memory paradigm, participants might be presented with the following words, all of which are related to the nonpresented critical word sleep: bed, rest, awake,

We thank Kavita Vakharia and Ben Yerys for their help on various aspects of this project including subject testing, data scoring, and recording of stimuli. We thank Martha Storandt for allowing us to use the Washington University Old Adult Subject Pool. We thank Andrew Budson, Dave McCabe, and John Seamon for helpful discussion of these results. We also thank Jeffrey Anastasi, David Gallo, Marcia Johnson, and an anonymous reviewer for helpful comments on an earlier version of this manuscript. This project was supported by National Institute on Aging Grant PO1 AGO3991 to D.A.B. J.M.W. is supported by a postdoctoral research fellowship from the McDonnell Center for Higher Brain Function. Correspondence should be addressed to J. M. Watson, Department of Psychology, Campus Box 1125, Washington University, One Brookings Drive, St. Louis, MO 63130-4899 (e-mail: jmwatson@ artsci.wustl.edu). tired, dream, wake, snooze, blanket, doze, slumber, snore, nap, peace, yawn, drowsy (see Deese, 1959; Roediger \& McDermott, 1995). As suggested by Balota, Cortese, et al. (1999), avoiding a false memory for a critical word requires one to differentiate between highly activated but nonpresented critical words and studied words. Hence, age-related increases in false memories may be due to a breakdown in control systems that differentiate the activation of critical words in internal, associative networks from the actual presentation of words at encoding (see Balota, Dolan, \& Duchek, 2000; Benjamin, 2001; Hasher \& Zacks, 1988; Hicks \& Marsh, 1999; Johnson, Hashtroudi, \& Lindsay, 1993; Roediger, Balota, \& Watson, 2001). In agreement with this idea, Sommers and Huff (2003) have recently shown that people's susceptibility to interference effects in the Stroop task correlates with their susceptibility to false memory effects.

\section{Can Old Adults Use Practice to Attenuate False Memories in the DRM Paradigm?}

Although several studies have demonstrated age-related increases in false memories, relatively few studies have explored the extent to which old adults can adopt strategies to attenuate the likelihood of these memory errors. Using a procedure developed by McDermott (1996) in which participants are given multiple study-test trials to learn associative materials, Kensinger and Schacter (1999) found that veridical recall and recognition increased across trials for both age groups, whereas false recall and recognition 
decreased across trials in young but not old adults (also see Budson et al., 2000). Age differences in the ability to reduce false memories via repeated study-test trials are consistent with an activation-monitoring framework of false memories recently proposed by McDermott and Watson (2001) and Roediger, Watson, McDermott, and Gallo (2001). Unlike young adults, old adults may experience a breakdown in source monitoring in that they fail to discriminate between activation that arises from study episodes and test trials. As such, old adults may use prior recall or recognition performance as an opportunity to encode previously remembered critical words that have not actually been presented.

\section{Can Old Adults Use Warnings to Reduce False Memories in the DRM Paradigm?}

In addition to benefiting from practice with the materials, young adults can also take advantage of explicit warning instructions given prior to encoding to reduce false memories in the DRM paradigm (see Gallo, Roberts, \& Seamon, 1997; Gallo, Roediger, \& McDermott, 2001; McDermott \& Roediger, 1998; Neuschatz, Benoit, \& Payne, 2003). Warnings inform participants that false memories are being elicited in the DRM paradigm via presentation of associates of a single nonpresented critical word. As suggested by Gallo et al. (1997), warning instructions at encoding may encourage participants to tag missing critical words as "not presented" during study, thereby minimizing the likelihood of false memories. Consistent with this idea, Neuschatz, Payne, Lampinen, and Toglia (2001) found that providing monitoring instructions at retrieval did not reduce false memories in young adults (also see Gallo et al., 2001). Although warning manipulations have been well investigated in young adults, only one published study has directly compared the effectiveness of warnings for reducing false memories across age groups. Specifically, McCabe and Smith (2002) recently found that old adults used warnings at encoding to reduce false recognition in the DRM paradigm.

\section{Comparing Warning and Practice Manipulations in the DRM Paradigm}

Collectively, the results of the aging and false memory studies reviewed above suggest an important distinction may exist between the strategic controlled processes emerging from experimenter-provided instructional manipulationswhich old adults are able to use effectively - and those selfinitiated controlled processes that can be employed under multiple study-test trials-which old adults appear not to be able to use. We speculate a bit about this distinction below but first point out that the strongest evidence for such a claim would emerge from a single study in which both findings were obtained (and not from cross-study comparisons). The present study was designed in part with this goal in mind.

If we were to indeed observe the predicted pattern (i.e., that old adults can take advantage of a warning but not multiple study-test trials to reduce false memories), it would suggest that old adults may be less likely than young adults to spontaneously engage in the monitoring needed to discriminate between what has been presented and what is strongly associated but not itself presented. That is, the ability to use practice to reduce false memories in the DRM paradigm may require self-initiated source monitoring. In contrast, old adults may be able to reduce false memories when the monitoring strategies are experimenter provided, as is the case with warnings. The predicted dissociation of warning and practice manipulations for old adults in the DRM paradigm is consistent with a contextual/environmental support framework of age-related memory decline. Specifically, Craik (1986) argued that age differences in episodic memory would be largest in tasks that demand self-initiated retrieval processes, whereas age differences would be minimized in tasks that provide retrieval support for old adults. Hence, the idea is that warnings may provide old adults with better contextual support than repeated study-test trials to help guide memory processing and to avoid false memories in the DRM paradigm.

\section{Overview of the Present Study}

To reiterate, the primary question posed by the present study was whether old adults would benefit from a warning but not multiple study-test trials when attempting to reduce false recall. This manipulation also allowed us to address whether the previous finding that old adults can benefit from an instructional warning prior to encoding would generalize from recognition (as found by McCabe \& Smith, 2002) to recall (as used in the present study). In addition, we examined whether young or old adults can better attenuate false recall when warnings and repeated study-test trials are combined in a single experiment. That is, will reductions observed in false recall across multiple study-test trials be magnified if a warning instruction is provided? To our knowledge, there has not been any evidence in the available literature of either young or old adults eliminating the robust false memories elicited by the DRM paradigm. However, young adults may use experimenter-provided warnings in conjunction with spontaneous, self-initiated source monitoring to greatly reduce or even eliminate false recall within the first few study-test trials. In contrast, although old adults may initially use detailed warnings at encoding as effectively as young adults, age differences may appear across trials to the extent that old adults are more likely than young adults to confuse their own recall performance with study episodes due to age-related breakdowns in selfinitiated source monitoring.

A final variable manipulated was presentation rate. We used two relatively slow presentation rates (1.25 and $2.5 \mathrm{sec} /$ word), primarily to determine whether old adults would show different patterns of results as a function of the two rates. Young adults have been shown to attenuate false recall as rates are slowed, at least in the range of rates used in the present study (Gallo \& Roediger, 2002; McDermott $\&$ Watson, 2001). Will old adults be able to enhance monitoring strategies when rates are slowed (and thereby reduce false recall)? The slower rate also allowed us to observe whether old adults may be able to attenuate false recall 
Table 1

Mean Veridical and False Recall Probabilities as a Function of Age, Study-Test Trial, Presentation Rate, and Instruction

\begin{tabular}{|c|c|c|c|c|c|c|}
\hline & \multicolumn{5}{|c|}{ Study-Test Trial } & \multirow[b]{2}{*}{$M$} \\
\hline & 1 & 2 & 3 & 4 & 5 & \\
\hline \multicolumn{7}{|c|}{ No Warning } \\
\hline \multicolumn{7}{|l|}{ Fast Rate } \\
\hline \multicolumn{7}{|l|}{ Young } \\
\hline Veridical & .28 & .51 & .67 & .74 & .80 & .60 \\
\hline False & .38 & .32 & .35 & .28 & .24 & .31 \\
\hline \multicolumn{7}{|l|}{ Old } \\
\hline Veridical & .21 & .32 & .38 & .46 & .51 & .38 \\
\hline False & .58 & .54 & .54 & .57 & .68 & .58 \\
\hline \multicolumn{7}{|l|}{ Slow Rate } \\
\hline \multicolumn{7}{|l|}{ Young } \\
\hline Veridical & .38 & .59 & .74 & .83 & .86 & .68 \\
\hline False & .44 & .31 & .25 & .28 & .19 & .29 \\
\hline \multicolumn{7}{|l|}{ Old } \\
\hline Veridical & .25 & .38 & .46 & .53 & .58 & .44 \\
\hline False & .38 & .29 & .35 & .25 & .24 & .30 \\
\hline \multicolumn{7}{|c|}{ Warning } \\
\hline \multicolumn{7}{|l|}{ Fast Rate } \\
\hline \multicolumn{7}{|l|}{ Young } \\
\hline Veridical & .28 & .49 & .64 & .70 & .75 & .57 \\
\hline False & .29 & .08 & .11 & .07 & .10 & .13 \\
\hline \multicolumn{7}{|l|}{ Old } \\
\hline Veridical & .21 & .36 & .46 & .52 & .56 & .42 \\
\hline False & .36 & .39 & .33 & .38 & .35 & .36 \\
\hline \multicolumn{7}{|l|}{ Slow Rate } \\
\hline \multicolumn{7}{|l|}{ Young } \\
\hline Veridical & .39 & .62 & .78 & .85 & .89 & .71 \\
\hline False & .25 & .06 & .08 & .08 & .03 & .10 \\
\hline \multicolumn{7}{|l|}{ Old } \\
\hline Veridical & .24 & .37 & .49 & .56 & .62 & .46 \\
\hline False & .14 & .22 & .15 & .17 & .15 & .17 \\
\hline
\end{tabular}

Note-Old adult false recall in the DRM paradigm decreased with slow $(2,500 \mathrm{msec} /$ word $)$ relative to fast $(1,250 \mathrm{msec} /$ word $)$ presentation rates, whereas young adult false recall was not influenced by this rate manipulation. Mean recall probabilities collapsed across study-test trial are shown in the far right-hand column.

across multiple study-test trials under the slower rate; this possibility is entertained in view of findings of age differences in processing speed (Salthouse, 1996). That is, it may be that when rates are sufficiently slow, old adults are able to use multiple study-test trials to attenuate false recall (even in the absence of warnings).

The present study addressed these research questions by factorially crossing warnings, study-test trials, and presentation rate to investigate veridical and false recall in both young and old adults.

\section{METHOD}

\section{Participants}

There were 144 participants tested in this experiment. Seventytwo of these individuals were undergraduates at Washington University, and 72 individuals were old adults recruited from the university community. Young adults either received course credit or were paid for their participation. All of the old adults were paid for their participation. The young adult age range was 18 to 27 years (mean age $=19.2$ years), whereas the old adult age range was 51 to 84 years (mean age $=73.3$ years). The old adult education range was comparable to that of typical, college-aged young adults, though in a small percentage of cases, the old adults were slightly more educated. Specifically, $81 \%$ of the old adults had completed $12-16$ years of education, $15 \%$ had completed $17-21$ years of education, and $4 \%$ had an unknown level of education.

\section{Materials}

Four 15-word sets of associates were blocked according to their related critical word (i.e., smell, doctor, window, and sleep, where smell was the corresponding critical word from the first set of 15 associates, doctor for the next set of 15 associates, etc.). These four lists and critical words elicit robust levels of false recall (i.e., $\geq .60$ ) in normative data collected on young adults (see Stadler, Roediger, \& McDermott, 1999). The 60 -word list was digitally recorded in a male voice, and the same recording was used for all study phases. Stimuli were presented through headphones worn by participants.

\section{Procedure}

For half of the young and old adults, the 60-word list was presented at an approximate rate of 1 word every $2.5 \mathrm{sec}$. For the remaining half of each age group, the 60-word list was presented at an approximate rate of 1 word every $1.25 \mathrm{sec}$. Half of the young and old adults within each presentation rate were given explicit warning instructions about the DRM paradigm prior to encoding. The remaining half of the young and old adults within each presentation rate were not given any warning. The between-subjects factorial crossing of age, presentation rate, and warning yielded a total of 18 participants per cell. Study-test trial was manipulated within subjects.

The warning manipulation was modeled after the instructions used by Gallo et al. (1997) and McDermott and Roediger (1998). Participants were warned that the forthcoming associative lists were designed to elicit false memories for particular critical words that had never been presented. Participants were encouraged to avoid recalling the "trick word" for each of the four sets of 15 words that had been combined to form the 60 -word list. To make this warning more concrete, participants were given a sample list (i.e., chair; see Stadler et al., 1999) at the same presentation rate as the forthcoming study list. Hence, if participants suspected that a critical word had merely been suggested, it would have always been correct to omit this word during free recall (see Gallo et al., 2001; McDermott \& Roediger, 1998, for additional discussion of methodological issues regarding the presence of critical words in DRM experiments that use warnings). Nonwarned participants were also informed that they would receive sets of associate lists and also received the sample list (but chair was not identified as a nonpresented "trick word," as it was for warned participants).

Participants were given a recall packet that contained five different response sheets with 60 numbered blanks per sheet. Before each of five study episodes, warned participants were instructed about the tendency for DRM lists to elicit recall of "trick words." All participants were told not to guess during the recall task. Following each of five study trials, participants were given 5 min to recall as many words as possible from the immediately previous study episode.

\section{RESULTS}

The mean veridical and false recall probabilities are presented in Table 1 as a function of age, study-test trial, presentation rate, and instruction. Separate 5 (study-test trial: $1-5) \times 2$ (instruction: warning and no warning $) \times 2$ (age: young and old) $\times 2$ (presentation rate: fast and slow) mixed-factor analyses of variance (ANOVAs) were conducted for veridical and false recall, respectively. Veridical and false recall probabilities are also presented in Figure 1 as a function of age, study-test trial, and instruction (collapsed across presentation rate). Unless otherwise noted, the 

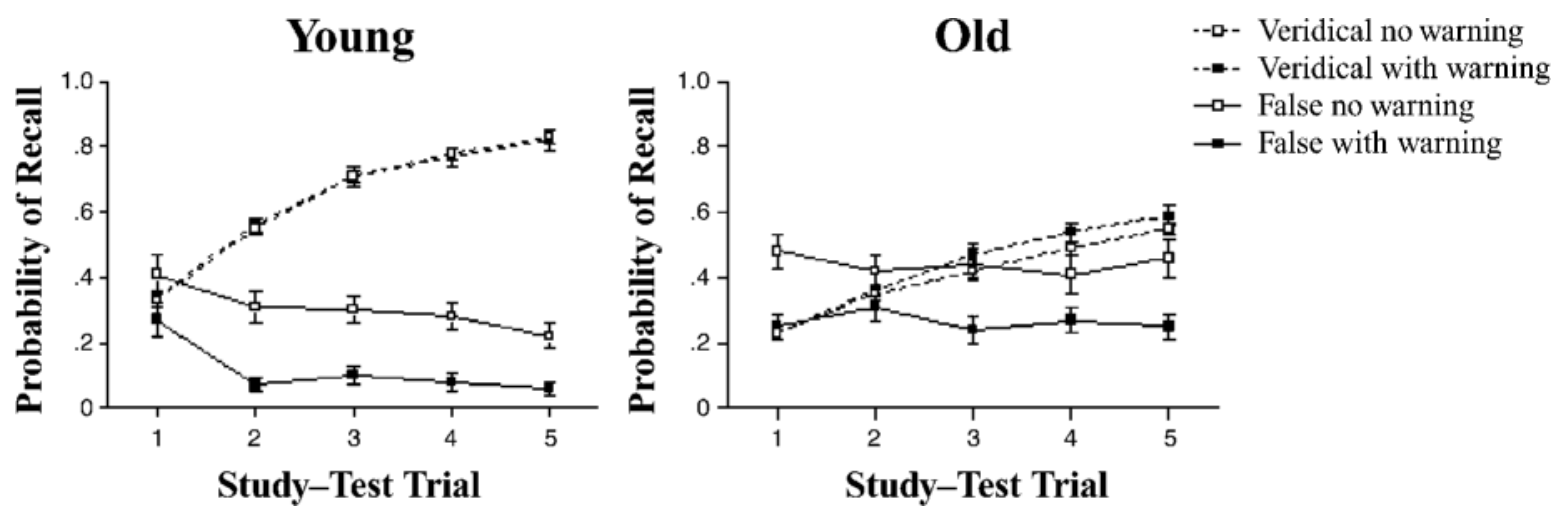

\begin{abstract}
Figure 1. Mean probability of veridical and false recall as a function of age, study-test trial, and instruction. Error bars represent the standard error of the mean. An age-related dissociation was observed. Young adults (left panel) used warnings in conjunction with practice to virtually eliminate false recall, whereas old adults (right panel) used warnings but not practice to reduce false recall in the DRM paradigm.
\end{abstract}

criterion for significance was set at .05 for all analyses discussed below.

\section{Veridical Recall}

There are three important points to note about the veridical recall probabilities presented in Table 1 and Figure 1. First, as shown in Table 1, the probability of veridical recall was greater for slow than for fast presentation rates. Second, veridical recall increased with repeated study-test trials for young and old adults in both the warning and nowarning conditions (although veridical recall exhibited a larger increase for young [.33-.82] than for old [.23-.57] adults across trials). Third, and most importantly, there was virtually no influence of the warning on veridical recall for either young or old adults. Specifically, young adult veridical recall increased from .33 to .83 and from .34 to .82 for Study-Test Trials $1-5$ in the no-warning and warning conditions, respectively. Comparable veridical recall probabilities for old adults were .23-.55 and .23-.59 for Study-Test Trials 1-5 in the no-warning and warning conditions, respectively. Clearly, these patterns of veridical recall indicate that participants were not simply adopting a conservative criterion in the warning condition to avoid recalling the nonpresented critical words. If anything, as shown in Figure 1, old adults elevated their veridical recall probability across the last few study-test trials when given a warning prior to encoding, whereas young adult veridical recall was relatively unaffected by the warning instructions across trials. Consistent with the preceding observations, the ANOVA on veridical recall revealed main effects of study-test trial $\left[F(4,544)=1,142.41, M S_{\mathrm{e}}=0.004\right]$, age $\left[F(1,136)=125.18, M S_{\mathrm{e}}=0.068\right]$, and presentation rate $\left[F(1,136)=15.95, M S_{\mathrm{e}}=0.068\right]$. The two-way interaction between age and study-test trial was significant $[F(4,544)=$ $\left.48.77, M S_{\mathrm{e}}=0.004\right]$, indicating that young adults improved their veridical recall across trials more than old adults did. The three-way interaction among age, study-test trial, and warning was also significant $\left[F(4,544)=2.43, M S_{\mathrm{e}}=\right.$ $0.004]$, indicating that old adults did not increase their veridical recall across trials as much in the no-warning as in the warning condition (whereas this difference did not occur in young adults). The remaining main effects and interactions in this ANOVA did not approach significance (all $p \mathrm{~s}>.14$ ).

\section{False Recall of Critical Words}

There are four important points to note about the false recall probabilities presented in Table 1 and Figure 1. First, young adults reduced false recall of critical words with multiple study-test trials, but old adults did not. Specifically, the probability of false recall decreased from the first to the fifth study-test trial for young adults in both the no-warning (.41-.22) and warning (.27-.06) conditions, whereas false recall was relatively stable across trials for old adults in both the no-warning (.48-.46) and warning (.25-.25) conditions. Second, both young and old adults reduced, but did not eliminate, false recall when warnings were provided before the first study trial at encoding (see Study-Test Trial 1, Figure 1). Hence, as predicted, the results of the present study yielded an age-related dissociation. That is, old adults benefited from warnings but not practice with the DRM lists when attempting to reduce false recall (whereas young adults benefited from both manipulations). Third, as shown in Table 1, old adult false recall decreased from .47 in the fast presentation condition to .22 in the slow presentation condition, whereas young adult false recall was not influenced by this manipulation ( $\cong .21$ for both rates). Fourth, even though false memories were initially reduced on Study-Test Trial 1 in warned old adults relative to nonwarned old adults, false recall for warned old adults remained relatively constant across five study-test trials $(\cong .25)$. Thus, the warning and practice manipulations did not interact for old adults. In contrast, as shown in Figure 1, young adults used the warning in conjunction with practice to virtually eliminate false recall by the second trial (.07).

In agreement with the preceding observations, the ANOVA on false recall revealed main effects of trial 
$\left[F(4,544)=7.26, M S_{\mathrm{e}}=0.034\right]$, instruction $[F(1,136)=$ $\left.35.46, M S_{\mathrm{e}}=0.169\right]$, age $\left[F(1,136)=21.97, M S_{\mathrm{e}}=0.169\right]$, and presentation rate $\left[F(1,136)=18.31, M S_{\mathrm{e}}=0.169\right]$. The two-way interactions between age and study-test trial $\left[F(4,544)=5.37, M S_{\mathrm{e}}=0.034\right]$ and between age and presentation rate $\left[F(1,136)=12.32, M S_{\mathrm{e}}=0.169\right]$ were both significant. None of the remaining interactions in this ANOVA approached significance (all $p$ s $>.33$ ), with the exception of the three-way interaction of age, study-test trial, and instruction $\left[F(4,544)=2.11, M S_{\mathrm{e}}=0.034, p<.08\right]$. As shown in Figure 1, young adults appeared to reduce false recall most effectively with warnings and practice combined, whereas old adults only appeared to use the warnings to reduce false recall (without any modulation in false recall across repeated study-test trials). The statistical significance of this three-way interaction may have been compromised somewhat by floor effects in young adult false recall, which had already been reduced to .07 by the second trial. To address this possibility, a second ANOVA was conducted that included only false recall performance on the first and second study-test trials. As expected, a qualitatively similar pattern of results emerged in this second ANOVA, although the three-way interaction of age, study-test trial, and instruction was now significant $\left[F(1,136)=5.58, M S_{\mathrm{e}}=0.039\right]$.

\section{Other Noncritical Word Intrusions}

A 5 (study-test trial: $1-5) \times 2$ (instruction: warning and no warning) $\times 2$ (age: young and old) $\times 2$ (presentation rate: fast and slow) mixed-factor ANOVA was also conducted on the raw number of intrusions (not including recall of critical words). This ANOVA revealed main effects of trial $\left[F(4,544)=35.53, M S_{\mathrm{e}}=1.29\right]$, instruction $\left[F(1,136)=3.95, M S_{\mathrm{e}}=6.89\right]$, age $\left[F(1,136)=23.04, M S_{\mathrm{e}}=\right.$ $6.89]$, and presentation rate $\left[F(1,136)=9.94, M S_{\mathrm{e}}=6.89\right]$. The raw number of intrusions per test decreased with repeated study-test trials (2.23-0.79 words per person per list of 60 words). The remaining three main effects were qualified by the two-way interactions between age and instruction $\left[F(1,136)=6.68, M S_{\mathrm{e}}=6.89\right]$ and between age and presentation rate $\left[F(1,136)=4.91, M S_{\mathrm{e}}=6.89\right]$. Old adults overall decreased their intrusions with warnings and with slow presentation rates, whereas young adult intrusions were relatively unaffected by these two variables. None of the remaining interactions in this ANOVA approached significance (all $p \mathrm{~s}>.10$ ).

\section{GENERAL DISCUSSION}

The present study addressed the extent to which young and old adults would take advantage of the combined influence of warnings and practice to reduce false recall in the DRM paradigm. There were three main findings in this experiment. First, and most importantly, we obtained an age-related dissociation such that old adults used warnings but not practice to reduce false recall (Figure 1), whereas young adults took advantage of both manipulations. Second, old but not young adults benefited from a slower pre- sentation rate to reduce false recall (Table 1). Third, as shown in Figure 1, young adults used warnings in conjunction with practice to virtually eliminate false recall by the second trial.

\section{Repeated Study-Test Trials, Aging, and False Memories in the DRM Paradigm}

An activation-monitoring framework of aging and false memories rests on the assumption that spreading activation in underlying associative networks of old adults is relatively intact, as evidenced by their robust semantic priming effects (e.g., see Balota, Watson, Duchek, \& Ferraro, 1999). However, there may be age-related breakdowns in spontaneous, self-initiated source monitoring (Johnson et al., 1993). Specifically, old adults may have difficulty spontaneously distinguishing between the presentation of words and their own thoughts at encoding, particularly for highly activated critical words in the DRM paradigm. Furthermore, once an item has been recalled, old adults may not discriminate between information that arises from study episodes and information that arises from test trials. Hence, in studies that use repeated study-test trials, old adults may use their own recall or recognition performance as an additional opportunity to encode critical words. In contrast, young adults may use repeated study-test trials to verify what is presented and what is strongly associated but not presented, gradually improving their veridical recall while concurrently diminishing their false recall with practice.

Practice might be an effective way to reduce false memories in old adults if the intervening memory tests were removed. That is, without intervening tests, old adults may be less likely to confuse their own output of critical words with actual study episodes. Consistent with this prediction, Budson et al. (2002) found that old adults who received five study trials and a final memory test without intervening tests reduced, but did not eliminate, false recognition of critical words relative to a control group of old adults who received only a single study trial and a final test. This reduction may also be due in part to Budson et al.'s use of different orienting instructions for each of the five study sessions (e.g., attending to the sound or appearance of the associates).

\section{Warnings, Aging, and \\ False Memories in the DRM Paradigm}

A warning manipulation explicitly instructs participants that DRM lists are designed to converge upon nonpresented critical words with the intent of eliciting false memories. Unlike repeated study-test trials, where participants must discriminate between studied words and critical words spontaneously, warnings are experimenter provided. As suggested by Gallo et al. (1997), warnings may encourage participants to monitor and prevent the initial output of some critical words by tagging them as "not presented" during study. To the extent that old adults have deficits in self-initiated source monitoring, one might expect old adults to benefit from detailed, experimenter-provided warnings at encoding. Consistent with this idea, as shown 
in Figure 1, old adults used the warning to reduce false recall (.23) as much, if not more, than young adults (.14) on the first trial. In fact, warned young and old adults had roughly equivalent false recall probabilities on the first trial (@.26), even though these two groups varied considerably in their veridical recall (.34 vs. .23 , respectively).

Hence, the results of the present study extend the recognition findings of McCabe and Smith (2002) by demonstrating that old adults can also use warnings to reduce false recall in the DRM paradigm. Moreover, these findings cannot be attributed to a criterion shift, because veridical recall was relatively unaffected by the presence of the warning for both age groups (though veridical recall actually increased slightly across the last few study-test trials for warned old adults). Within Craik's (1986) contextual/ environmental support framework of age-related memory decline, the present results suggest that warnings provide old adults with better contextual support than repeated study-test trials to help guide memory processing and to avoid false memories in the DRM paradigm.

\section{Presentation Rate, Aging, and \\ False Memories in the DRM Paradigm}

As shown in Table 1, old adult false recall decreased from .47 to .22 with fast $(1,250 \mathrm{msec} /$ word $)$ relative to slow $(2,500 \mathrm{msec} /$ word $)$ presentation rates, whereas young adult false recall was not influenced by this manipulation ( $\cong .21$ for both rates). These results provide additional support for the idea that old adults can successfully reduce the likelihood of false memories for critical words in the DRM paradigm when given sufficient time to monitor the source of information. According to a general slowing framework of cognitive aging (Salthouse, 1996), young and old adults should perform similarly on cognitive tasks after age differences in processing speed have been adjusted for. However, it is noteworthy that even in the slow presentation condition, old adults did not decrease their false recall across repeated study-test trials. Furthermore, old adults were able to reduce false recall with warnings, independent of presentation rate.

There are three other important points to note about these presentation rate results. First, young adults did not reduce false recall with this rate manipulation. However, McDermott and Watson (2001) have shown that young adult false recall in the DRM paradigm rises and falls with increasing presentation durations of 20, 250, 1,000, 3,000, and 5,000 msec (also see Gallo \& Roediger, 2002). Had we used a fuller range of presentation rates in the present study, it is likely that we would have observed both an increase and a decrease in false recall in our young adults. More importantly, as demonstrated by the results in Table 1, the optimal range of presentation rates for observing effects on false recall appears to be different for young and old adults. Second, these presentation rate results extend the recognition findings of McCabe and Smith (2002). Specifically, McCabe and Smith did not observe an effect of presentation rate on false recognition for old adults. However, McCabe and Smith used a different range of pre- sentation rates ( 2,000 vs. $4,000 \mathrm{msec} /$ word) to investigate false recognition than we used to investigate false recall $(1,250$ vs. $2,500 \mathrm{msec} /$ word $)$. The range used by McCabe and Smith may not have been optimal to observe age differences in the developmental time course of controlled processing. Third, comparable effects of presentation rate were observed for young and old adults in both false recall of critical words and noncritical word intrusions. Specifically, there were fewer intrusions for old adults with the slow relative to the fast rate, but there was no effect of this manipulation on young adult intrusions. One might argue that this pattern of memory performance across critical word false recall and intrusions represents a criterion shift for the old adults (i.e., more conservative responding, in general, for slow relative to fast presentation rates). However, caution is warranted in interpreting these intrusion data, since the mean raw number of intrusions for young (.84 items/test) and old ( 1.79 items/test) adults collapsed across the other independent variables was quite low given that participants studied a 60 -item word list at encoding.

\section{Combined Effects of Practice and Warnings on False Memories in Young and Old Adults}

The present study is the first to address the combined influence of warnings and practice in the DRM paradigm. Repeated study-test trials may require spontaneous, selfinitiated source monitoring, whereas experimenter-provided warnings explicitly instruct participants that DRM lists are designed to converge upon nonpresented critical words. However, the overarching goal of both manipulations is to monitor and systematically attenuate memory errors. In this light, it is interesting that young adults used practice in conjunction with warnings to virtually eliminate false recall by the second trial, whereas these two manipulations did not produce a combined effect for old adults. Specifically, as shown in Figure 1, veridical recall was equivalent on the second study trial in the warning and no-warning conditions for young adults (.56), whereas false recall approached floor levels (.07) when young adults were given a warning (relative to false recall of .31 without a warning). Although old adult false recall was initially reduced with a warning on Study-Test Trial 1 for both the fast and slow presentation rates, it remained relatively constant across

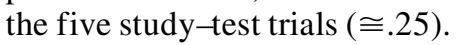

Within a source-monitoring framework (see Johnson et al., 1993), warnings may encourage participants to direct their attention to nonsemantic, perceptual dimensions of the studied associates (e.g., orthography and phonology) in order to discriminate between what has been presented and what has merely been activated by the associative list context. As such, both young and old adults may benefit initially from warnings, with perhaps a larger benefit for old adults (who may be more susceptible to the illusion under standard learning conditions without warnings due to age-related breakdowns in self-initiated source monitoring). However, once a critical word has been output on the first test trial and has accumulated a source of perceptual information, as shown in Figure 1, old adults 
appear to have difficulty discriminating between studied words and nonpresented critical words. In contrast, warned young adults can spontaneously discount the perceptual support for critical words provided by their own output in favor of the perceptual information provided by additional study episodes. Hence, young adults can use warnings in conjunction with practice to virtually eliminate the robust false memories typically observed with associative lists in the DRM paradigm.

\section{REFERENCES}

Balota, D. A., Cortese, M. J., DucheK, J. M., Adams, D., Roediger, H. L., III, MCDERmotT, K. B., \& YerYs, B. E. (1999). Veridical and false memories in healthy older adults and in dementia of the Alzheimer's type. Cognitive Neuropsychology, 16, 361-384.

Balota, D. A., Dolan, P. O., \& DucheK, J. M. (2000). Memory changes in healthy older adults. In E. Tulving \& F. I. M. Craik (Eds.), The Oxford handbook of memory (pp. 395-409). New York: Oxford University Press.

Balota, D. A., Watson, J. M., Duchek, J. M., \& Ferraro, F. R. (1999). Cross-modal semantic and homograph priming in healthy young, healthy old, and in Alzheimer's disease individuals. Journal of the International Neuropsychological Society, 5, 626-640.

BENJAMIN, A. S. (2001). On the dual effects of repetition in false recognition. Journal of Experimental Psychology: Learning, Memory, \& Cognition, 27, 941-947.

Budson, A. E., Daffner, K. R., Desikan, R., \& Schacter, D. L. (2000). When false recognition is unopposed by true recognition: Gist-based memory distortion in Alzheimer's disease. Neuropsychology, 14, 277-287.

Budson, A. E., Sullivan, A. L., Mayer, E., Daffner, K. R., Black, P. M., \& SCHACTER, D. L. (2002). Suppression of false recognition in Alzheimer's disease and in patients with frontal lobe lesions. Brain, 125, 2750-2765.

CRAIK, F. I. M. (1986). A functional account of age differences in memory. In F. Klix \& H. Hagendorf (Eds.), Human memory and cognitive capabilities, mechanisms, and performances (pp. 409-422). Amsterdam: Elsevier, North-Holland.

DEESE, J. (1959). On the prediction of occurrence of particular verbal intrusions in immediate recall. Journal of Experimental Psychology, 58, 17-22.

Gallo, D.A., Roberts, M. J., \& SeAmon, J. G. (1997). Remembering words not presented in lists: Can we avoid creating false memories? Psychonomic Bulletin \& Review, 4, 271-276.

GAllo, D. A., \& Roediger, H. L., III (2002). Variability among word lists in eliciting memory illusions: Evidence for associative activation and monitoring. Journal of Memory \& Language, 47, 469-497.

Gallo, D. A., Roediger, H. L., III, \& MCDermott, K. B. (2001). Associative false recognition occurs without strategic criterion shifts. Psychonomic Bulletin \& Review, 8, 579-586.

HASHER, L., \& ZACKS, R. T. (1988). Working memory, comprehension, and aging: A review and a new view. In G. H. Bower (Ed.), The psychology oflearning andmotivation (Vol.22, pp. 193-225).San Diego: Academic Press.

HICKS, J. L., \& MARSH, R. L. (1999). Attempts to reduce the incidence of false recall with source monitoring. Journal of Experimental Psychology: Learning, Memory, \& Cognition, 25, 1195-1209.

Johnson, M. K., Hashtroudi, S., \& Lindsay, D. S. (1993). Source monitoring. Psychological Bulletin, 114, 3-28.

Kensinger, E. A., \& Schacter, D. L. (1999). When true memories suppress false memories: Effects of ageing. Cognitive Neuropsychology, 16, 399-415.

MCCABE, D. P., \& SMITH, A. D. (2002). The effect of warnings on false memories in young and older adults. Memory \& Cognition, 30, 1065 1077.

MCDERmott, K. B. (1996). The persistence of false memories in list recall. Journal of Memory \& Language, 35, 212-230.

MCDermott,K. B., \& Roediger, H. L., III (1998). Attempting to avoid illusory memories: Robust false recognition of associates persists under conditions of explicit warnings and immediate testing. Journal of Memory \& Language, 39, 508-520.

MCDERmotT, K. B., \& WATSOn, J. M. (2001). The rise and fall of false recall: The impact of presentation duration. Journal of Memory \& Language, 45, 160-176.

Neuschatz, J. S., Benoit, G. E., \& Payne, D. G. (2003). Effective warnings in the Deese-Roediger-McDermott false-memory paradigm: The role of identifiability. Journal of Experimental Psychology: Learning, Memory, \& Cognition, 29, 35-41.

Neuschatz, J. S., Payne, D. G., Lampinen, J. M., \& Toglia, M. P. (2001). Assessing the effectiveness of warnings and the phenomenological characteristics of false memories. Memory, 9, 53-71.

Norman, K. A., \& Schacter, D. L. (1997). False recognition in younger and older adults: Exploring the characteristics of illusory memories. Memory \& Cognition, 25, 838-848.

Roediger, H. L., III, BALOtA, D. A., \& WATSON, J. M. (2001). Spreading activation and arousal of false memories. In H. L. Roediger III, J. S. Nairne, I. Neath, \& A. M. Surprenant (Eds.), The nature of remembering: Essays in honor of Robert G. Crowder (pp. 95-115). Washington, DC: American Psychological Association.

RoEdiger, H. L., III, \& MCDERMOTT, K. B. (1995). Creating false memories: Remembering words not presented in lists. Journal of Experimental Psychology: Learning, Memory, \& Cognition, 21, 803-814.

Roediger, H. L., III, Watson, J. M., McDermott, K. B., \& Gallo, D. A. (2001). Factors that determine false recall: A multiple regression analysis. Psychonomic Bulletin \& Review, 8, 385-407.

SAlthouse, T. A. (1996). The processing speed theory of adult age differences in cognition. Psychological Review, 103, 403-428.

Sommers, M. S., \& HufF, L. M. (2003). The effects of age and dementia of the Alzheimer's type on phonological false memories. Psychology \& Aging, 18, 791-806.

Stadler, M. A., Roediger, H. L., III, \& McDermott, K. B. (1999). Norms for word lists that create false memories. Memory \& Cognition, 27, 494-500.

Tun, P. A., Wingfield, A., Rosen, M. J., \& Blanchard, L. (1998). Response latencies for false memories: Gist-based processes in normal aging. Psychology \& Aging, 13, 230-241.

Watson, J. M., Balota, D. A., \& Sergent-Marshall, S. D. (2001). Semantic, phonological, and hybrid veridical and false memories in healthy older adults and in individuals with dementia of the Alzheimer type. Neuropsychology, 2, 254-267.

(Manuscript received January 2, 2003; revision accepted for publication August 6, 2003.) 